\title{
On Entrained Pore Size Distribution of Foamed Concrete
}

\author{
Ameer A. Hilal*, Nicholas Howard Thom, Andrew Robert Dawson
}

Department of Civil Engineering, Faculty of Engineering, University of Nottingham, University Park, Nottingham NG7 2RD, UK Tel: +44 (0) 115846 8427, Fax: +44 (0) 115 951 3909, E-mail: evxaah@nottingham.ac.uk

*Corresponding author

\section{Abstract}

The pore structure of foamed concrete is a significant characteristic since it affects properties such as strength and durability. To investigate these properties, the determination of total air voids content is not sufficient as the shape, size and distribution of air voids may also be influential. To understand the formation of voids after hardening, an investigation of the bubble size distribution of foam (before adding to the mixture) and the pore size distribution of the foamed concrete mixes (after hardening) is discussed in this paper. These distributions have been quantified by examining selected size parameters to make a comparison between them. In addition, void circularity factors have been determined to examine the phenomenon of voids merging. In order to investigate the foam structure before adding to the mix, it was found that by treating the foam with bitumen emulsion, a clear image of its structure can be captured using an optical microscope. Using this technique, a significant difference was found between the size distribution of foam bubbles and those of air pores within foamed concrete mixes. From circularity factor results, there is evidence for increased bubble merging with increased added foam volume (decreased density).

Keywords: Foamed concrete, Pore structure, Circularity factor, Optical microscope, Image processing. 
Foamed concrete is a versatile material consisting of either Portland cement paste or cement filler matrix (mortar) with homogeneous pore structure created by entrained air voids roughly 0.1-1.0 mm size [1-4]. Nambiar and Ramamurthy [1], reported that the introduction of pores inside foamed concrete can be achieved mechanically either by preformed foaming (forming the foam before adding it to the mix) or mix foaming (mixing in a foaming agent). It should be noted that the foamed concrete investigated in this study has been manufactured using the preformed foaming method.

The pore structure of cementitious material is a very significant characteristic since it affects properties such as strength and durability due to their dependence on material porosity and permeability [2]. However, determination of the total air void content (porosity) is not sufficient as shape, size and distribution of voids may affect the strength and durability of concrete [5].

Ramamurthy et al [2], mentioned that the air-void distribution is one of the most significant micro-properties influencing the strength of foamed concrete and concluded that foamed concrete with a narrower air-void size distribution shows higher strength. It seems likely that the pore structure and microstructure of foamed concrete has an important influence on its properties. It is usually classified into gel pores $(<10 \mathrm{~nm})$, capillary pores $(<10 \mu \mathrm{m})$ and air voids (air entrained and entrapped pores). Although the gel pores do not influence the concrete strength, they are directly related to creep and shrinkage. On the other hand, capillary and other large pores are responsible for reduction in strength and elasticity [1]. In spite of this significant influence, evaluation of foamed concrete pore structure is seldom reported [6].

Nambiar and Ramamurthy [1] and Just and Middendorf [7] both mentioned that the pores of foamed concrete can be measured by several test methods such as: nitrogen gas absorptiondesorption, optical microscopy with image processing, mercury porosimetry and $\mathrm{X}$ ray computed tomography with image processing. In addition, for testing the pore structure and microstructure of foamed concrete, both scanning electron microscopy (SEM) and light microscopy combined with digital imaging were used by $\mathrm{Yu}$ et al, [6]. The results from both measurement techniques revealed that the pore diameters were mainly in the range of 100$200 \mu \mathrm{m}$. 
In their investigation into the microstructure of foamed concrete produced with the inclusion of either classified (pfa) and unclassified (Pozz-fill) fly ash, Kearesely [5] concluded that there was no obvious difference between the void sizes observed in the two mixes and that for a $1500 \mathrm{~kg} / \mathrm{m}^{3} \mathrm{mix}$, the entrained air void diameters varied between approximately 40 and $300 \mu \mathrm{m}$.

Nambiar and Ramamurthy [1] also determined the air void size distribution of foamed concrete mixes with different added foam volumes $(10 \%, 30 \%$ and $50 \%)$ and found that the size of the larger voids increased sharply with an increase in foam volume, while for the same foam volume they were smaller for a cement-fly ash mix compared to a cement-sand mix.

Thus, although the pore size distribution of foamed concrete has to some extent been investigated, a great deal remains to be understood, so this paper aims to investigate the formation of the voids during mixing. This is achieved by:

1) Determining and comparing the size distributions of air voids in the foamed concrete mixes (after hardening) to those of bubbles in the preformed foam based on both number and area of bubbles/voids.

2) Investigating the circularity of the voids within the mixes.

\section{Experimental details}

\subsection{Constituent materials}

The materials used were: ordinary Portland cement CEM I-52,5 N (3.15 S.G.) conforming to BS EN 197-1:2011 [8], natural fine aggregate (sand) (2.65 S.G.) conforming to BS 882:1992 [9], sieved to remove particles greater than $2.36 \mathrm{~mm}$ to help improve the flow characteristics and stability of the final product $[10,11]$, potable water and foam. Three mixes of foamed concrete were made with nominal densities of 1300,1600 and $1900 \mathrm{~kg} / \mathrm{m}^{3}$, designated FC3, FC6 and FC9. To achieve these target densities, the water cement ratios of these mixes were determined, by trials, ensuring the stability of the wet foamed concrete mix and also that the measured density was equal or nearly equal to the design density $[12,13]$. The materials required per $\mathrm{m}^{3}$ of the selected mixes were calculated using the absolute volume method. An ordinary mixer was used to produce foamed concrete in the laboratory by the addition of preformed foam to a base mortar (sand-cement) mix. The required amount of foam was generated and added to the base mix and mixed until the foam was uniformly distributed and incorporated into the mix [12]. The mix proportions of the foamed concrete mixes investigated are given in Table 1 per $\mathrm{m}^{3}$ of final concrete. 
94

Pre-formed foam (at $45 \mathrm{~kg} / \mathrm{m}^{3}$ ) produced by blending a foaming agent, EABASSOC (1.05 S.G.), water and compressed air at predetermined proportions of 55: 1 (water: foaming agent by volume) in a foam generator. A STONEFOAM-4 generator was used in this study.

About a litre of foam has been taken from the foam generator and then put in a cylindrical plastic container (50mm diameter and $20 \mathrm{~mm}$ height) for the foam surface microscopic investigation. Due to the impossibility of capturing a clear image of the foam in its natural state using an optical microscope with low magnification, in was decided to impregnate it with a very small dose of bitumen emulsion, see Figure (1). Bitumen emulsion was chosen since it contains carbon which, when using an optical microscope, gives an image with good clarity and contrast between the edges and surfaces of individual foam bubbles, see Figure (2). In addition, the production process of bitumen emulsion involves a surfactant (emulsifier) which surrounds individual bitumen droplets (of size $<10 \mu \mathrm{m}$ ) within the water, which is essentially the same mechanism as used in foam production, see Figure (3). The result is that the bitumen emulsion will be compatible with the foam and spread easily through the bubble membranes, giving them colour.

\section{- Foamed concrete}

For each foamed concrete mix, 3 slices $(50 \times 50 \times 15 \mathrm{~mm})$ were cut from the centres of three cured specimens, perpendicular to the cast face, and used for pore size investigation. To make the boundaries between the air voids and the matrix sharp and easily distinguishable, the specimens were first polished and cleaned to remove any residues. Then, to enhance the contrast, the specimen surfaces were treated by applying two coats of permanent marker ink to them. After placing them in an oven at $50^{\circ} \mathrm{C}$ for $4 \mathrm{hrs}$, a white powder (Sodium bicarbonate) with a minimum particle size $5 \mu \mathrm{m}$ was pressed into the surfaces of the specimens and forced into the voids. This left the concrete surface black and the voids white, resulting in specimens with excellent properties for image analysis. This technique is described more fully in EN 480-1 [14] and [1]. 
124 A camera connected to an optical microscope (MCA NIKON SMZ-10 STEREO) and a 125 computer was used to capture the images of both foam and foamed concrete mixes.

126 For the foam investigation, a magnification of (56x) was selected, with a pixel representing $1272.34 \mu \mathrm{m}$ and an image of $28.3 \mathrm{~mm}^{2}(6.14 \mathrm{~mm} \times 4.60 \mathrm{~mm})$. However, its proved impossible to 128 derive a binary image suitable for automated analysis (in ImageJ) and manual measurements 129 were therefore carried out to determine the void diameters (around 200 voids in each image) from the captured foam images.

131 For mixes, a magnification of $(23 \times)$ was selected with a pixel representing $6 \mu \mathrm{m}$ and an 132 image size of $178.52 \mathrm{~mm}^{2}(15.43 \mathrm{~mm} \times 11.57 \mathrm{~mm})$. This magnification was chosen in order 133 that air voids with diameters in excess of $20 \mu \mathrm{m}$ could be easily identified, see Section 3.2. 134 Ten images were captured for each mix and then digitized, converted into binary form and analysed. For this study, only two phases, air voids and solid, were of interest.

A histogram of gray levels from the optical microscope image was used to select the threshold value, below which all pixels were considered voids and above which they were considered as solid, creating the final binary image required for analysis. Although the grayscale histograms did not have a sharp boundary between the two phases (voids and matrix) interface, there was always a minimum in the boundary region and this was set as the threshold for analysis of the images in this study.

Although software operations such as dilation, erosion, opening, closing and hole filling have all been suggested as being useful in application to concrete microscopy [1], in this study, it was found that the simple operation of hole filling was sufficient since there is a sharp contrast between the white coloured air voids and the surrounding black coloured matrix. Typical binary images for the three investigated mixes are shown in Figure (4). 


\section{Results and discussion}

\subsection{Bubble size distribution of foam}

The bubble size distribution and the corresponding cumulative frequencies (on the basis of number of bubbles) for the foam images are shown in Figure (5). From this, it can be seen that the minimum bubble diameter is about $100 \mu \mathrm{m}$ and the largest is $875 \mu \mathrm{m}$ with a median diameter $\mathrm{D}_{50}$ of $325 \mu \mathrm{m}$ and a $90^{\text {th }}$ percentile $\left(\mathrm{D}_{90}\right)$ of $600 \mu \mathrm{m}$. However, it was observed that the natural surface of the foam formed in such a way as to conceal some of the smaller bubbles, and a second set of ten images was therefore captured from the same foam samples after applying a microscope glass slide to the surfaces, see Figure (6). From this figure, the membrane thickness between two bubbles is about $100 \mu \mathrm{m}$ and since the individual bitumen droplets are less than $10 \mu \mathrm{m}$, little effect on the observed bubble diameters is anticipated.

The numeric cumulative frequency curves for the foam with and without glass plate application are shown in Figure (7).

\subsection{Pore size distribution of foamed concrete}

For each void, an effective diameter was calculated by measuring the void area and assuming it to be perfect circle [5].

Figure (8) shows the resulting pore size distributions for foamed concrete mixes with densities of 1300, 1600 and $1900 \mathrm{~kg} / \mathrm{m}^{3}$ (mixes FC3, FC6 and FC9 respectively), where it may be seen that sizes vary between approximately 20 and $1950 \mu \mathrm{m}$. It is clear that at higher density, the proportion of the larger voids decreases leading to a narrower air void size distribution. In order to quantify and compare the air void distribution of different mixes, the parameters $\mathrm{O}_{50}$ (median opening pore size) and $\mathrm{O}_{90}\left(90^{\text {th }}\right.$ percentile) were calculated on the basis of number of voids, see Table 2; $\mathrm{O}_{50}$ varied from 165 to $180 \mu \mathrm{m}, \mathrm{O}_{90}$ from 525 to 750 $\mu \mathrm{m}$, and both $\mathrm{O}_{50}$ and $\mathrm{O}_{90}$ increased with foam volume. The smallest air void diameter identified was about $20 \mu \mathrm{m}$. To check that these smallest pores came from the added foam (entrained air voids) rather than from the manufacturing process (entrapped air voids), SEM images were captured from mortar mixes both with and without added foam, Figures (9) and (10). In Figure (10), it can be seen that there are very few entrapped air voids in the $20 \mu \mathrm{m}$ size range, leading to the conclusion that all pores in excess of $20 \mu \mathrm{m}$, clearly apparent in Figure (9), are foam pores. 
The calculations were repeated this time by calculating the O50 and O90 on the basis of the area contained within each void (see Table 2). This is discussed in the next section.

\subsection{Comparison}

Figure (8) illustrates the cumulative frequency of bubble/ pore diameters in the foam and the foamed concrete mixes (on the basis of number of bubbles/voids). Two very clear differences are apparent. First, foamed concrete mixes contain some larger sized pores than those in the foam itself and the number of such pores increasing with the increase in added foam volume. This is logical due to the combining of foam bubbles during and possibly after mixing. However, the second difference is much more substantial. From Figure (5), the smallest bubble diameter in the foam was about $100 \mu \mathrm{m}$, while in the foamed concrete mixes there were many voids with sizes lower than this value. Even when microscope glass slide was pressed into the foam surface, Figure (6), no more than $20 \%$ of bubbles were found to be smaller than $100 \mu \mathrm{m}$ (Figure 7) and it could be argued that this technique leads to bubble distension and an overestimation of bubble diameters. In contrast, 30-40\% of voids in the mixes had a diameter less than $100 \mu \mathrm{m}$. Looking at the $\mathrm{D}_{50}$ values, that for foam was 300-325 $\mu \mathrm{m}$, depending on the observational technique used, compared to $165-185 \mu \mathrm{m}$ for the mixes.

There are two possible reasons for this. Firstly; merging of large bubbles, by reducing the number of larger voids, reduces the total number of voids compared to that of foam bubble leading to an increase in the numeric proportion of the smallest voids and positioning the numeric cumulative curve for the mix above the curve for the foam.

Secondly, from a vacuum saturation test; it was found that the porosities of the mortars (without foam) are 14.6, 14.1 and $13.9 \%$ for FC3, FC6 and FC9 respectively. While for the FC3, FC6 and FC9 foamed concrete, they were 52.8, 40.9 and 29\%. By knowing the added foam (Table 1) and the difference between foamed concrete and corresponding mortar porosities, it was found that there is foam volume loss of about 4.2, 2.7 and 1.5\% for FC3, FC6 and FC9 respectively. This loss is probably because foam bubbles collapse or the air in them is lost to the atmosphere, and this is likely happening with the large bubbles. This will have the same effect of merging leading to the median diameter of foam bubbles $\left(D_{50}\right)$ being larger than those of the voids $\left(\mathrm{O}_{50}\right)$ in the mixes.

Another possible interpretation is that the loss of foam bubbles (by collapse) during the mixing process leaves a solution (foaming agent with water) which works as an air-entraining 
agent and produces, during mixing, other smaller bubbles. In this context, the addition of a foam stabilizer could usefully be investigated and the bubble size distribution in the hardened concrete examined.

In place of analysis of numbers of bubbles at each diameter, the same data was considered from the prospective of the area of the bubbles in the foam and the concrete images. Figure (11) shows the frequency and cumulative frequency by area of the bubbles in the foam. This may be contrasted with the numeric frequency previously presented in Figure (5). A low number of larger bubbles (Figure 5) means that the area contained within these bubbles comprises a significant proportion of the space occupied by the foam, as seen in Figure (11) between 550 and $875 \mu \mathrm{m}$. This has the effect of increasing the $\mathrm{D}_{50}$ calculated on the basis area $(470 \mu \mathrm{m})$ from the value of $325 \mu \mathrm{m}$ calculated on the basis of number of bubbles (Table 2). Because in concrete the larger bubbles are more implicated in the development of cracking and, hence, strength reduction, the characterisation by bubble area is probably to be preferred. Continuing this argument, characterization by, for example, $\mathrm{D}_{90}$ may be more germane.

A comparison of foam bubble area and concrete mix pore area is included in Table 2. It shows that both median and large characteristic voids are significantly greater in area than in the foam. This implies that there has been significant merging of small voids into a few larger voids during the concrete mixing process. This behaviour is most pronounced in the least dense mix.

Considering this observation with the early one that median pore size based on number of pores reduces, comparison of Figures (8) and (12) allows us to deduce that bubble merging is prevalent in all mixes. In the less dense mixes, bubble merging takes place at all sizes (the cumulative area void curve for the concrete is always beneath that for the foam). In the most dense mix the area contained in small pores does not change much at all, indicating that the small bubbles result in small pores without much loss to merged bubbles.

In the most dense mix, since the voids merging of larger voids is less than in the lighter mixes, loss of voids must be more effective than their merging in making the mix curve lie above the foam curve within the small diameter range (Figure 12). 
243 Considering all the foamed concretes in Figure (12), the small or absence of curve increase

244 in the small diameter range indicates that bubble splitting/shrinkage does not occur in any 245 mixes or if it does, bubble merging offsets its effect.

\subsection{Pore Circularity}

247 The circularity factor $\left(\mathrm{F}_{\text {circ }}\right)$ is the function of a perimeter and surface area of each pore, 248 defined as follows;

$$
F_{\text {circ }}=4 \pi\left[\frac{\text { Area }}{\text { perimeter }^{2}}\right]
$$

250 Circularity factor equals 1 for a perfect circular pore and it is smaller for irregular shapes 251 [15].

252

253

254

255

256

257

From the SEM images for foamed concrete mixes (Figure (8)), it can be seen that the voids shape, at high magnification (> 500x), is almost circular which means that their circularity factor should be near to 1 . However, with the optical microscope (at low magnification, $<25 x)$; voids with irregular shapes, formed due to bubble merging, can clearly be seen; see Figure (4) supported by lower magnification SEM images in Figure (13). From image analysing results, Figure (14) shows that void merging is more frequent with decreased added foam volume. Therefore, the $\mathrm{F}_{\text {circ50 }}$ and $\mathrm{F}_{\text {circ90 }}$ for FC9 are higher than those of FC3; see cumulative frequency curves in Figure (14) and Table (2). This effect, bubble merging, is likely to be a primary reason that the porosity values (36.6, 25 and 14 for FC3, FC6 and FC9 respectively) calculated by image analysis were lower than the added foam volumes (42.4, 29.5 and 16.6), a reason also suggested by Nambiar and Ramamurthy [1], and the difference increases with increased added foam (decrease in density).

(1)

.


272 From the tests presented in this paper and based on the above results and discussion, the 273 following conclusions can be drawn:

274 - By treating with bitumen emulsion, a clear image, of foam bubbles shape and distribution, can be captured using an optical microscope.

- There is a difference between the size distribution of bubbles within preformed foam and those of pores in foamed concrete mixes.

- Compared to the foam bubble size distribution, some larger sized pores were presented in foamed concrete mixes owing to the merging of bubbles during mixing.

- Bubble merging in all mixes is relatively significant, the greater merging being observed in the lowest density mixes, but only larger bubbles appear to participate in their merging.

- All foamed concrete mixes investigated also contained a higher proportion of smallsized voids compared to the preformed foam, meaning that the $\mathrm{D}_{50}$ of the foam was larger than that of all investigated mixes. This is likely due to merging and losing of bubbles during mixing.

- Bubble splitting or shrinkage does not appear to be significant in any mix or if it does, bubble merging and loss offsets its effect.

- For foamed concrete mixes (on the basis of number or area of voids), $\mathrm{O}_{50}$ and $\mathrm{O}_{90}$ both decrease with decreased added foam volume (increase in density).

- Although both in the foam and in the concrete mixes made with the foam the median $\left(D_{50}\right)$ bubble/void is relatively small when the overall number of bubbles is monitored, yet there are a small number of larger bubbles/voids which, by virtue of their size, contribute a significant proportion of the area (and hence volume) of voids in the concrete mixes. Because larger voids are more implicated in concrete weakness, it is recommended that definition of voids on the basis of area is to be preferred.

- From circularity factor results, the evidence for bubbles merging is higher with increased added foam volume (decrease in density).

This study has suggested a number of avenues for future research including:

- Using different doses of the bitumen emulsion and investigating their effect on the observed bubbles thickness.

- Addition of foam stabilizer and its effect on bubble size distribution in hardened concrete. 


\section{Acknowledgements}

The authors would like to acknowledge the support of the Higher Committee for Education Development in Iraq (HCED) for the research scholarship enabling this work to be conducted as part of a larger research project. The authors also wish to thank Dr Daniel Wells (E-A-B Associates Company, UK) for providing the foaming agent. Finally, the valuable help and comments of Mr Keith Dinsdale (University of Nottingham) during the microscopy observation and Mr Martin Roe (University of Nottingham) during the SEM test are gratefully acknowledged.

Table 1. Mix proportions of selected foamed concrete mixes.

\begin{tabular}{lccc}
\hline & \multicolumn{3}{c}{ Mixes } \\
\cline { 2 - 4 } & FC3 & FC6 & FC9 \\
\hline Target density $\left(\mathbf{k g} / \mathbf{m}^{3}\right)$ & 1300 & 1600 & 1900 \\
Cement content $\left(\mathbf{k g} / \mathbf{m}^{3}\right)$ & 500 & 500 & 500 \\
W/C ratio & 0.475 & 0.5 & 0.525 \\
Water content $\left(\mathbf{k g} / \mathbf{m}^{3}\right)$ & 237.5 & 249.9 & 262.5 \\
Sand content $\left(\mathbf{k g} / \mathbf{m}^{3}\right)$ & 562 & 850 & 1137.5 \\
Foam $\left(\mathbf{l} / \mathbf{m}^{\mathbf{3}}\right)$ & 424 & 295 & 166 \\
Foaming agent $\left(\mathbf{k g} / \mathbf{m}^{3}\right)$ & 0.35 & 0.24 & 0.14 \\
\hline
\end{tabular}

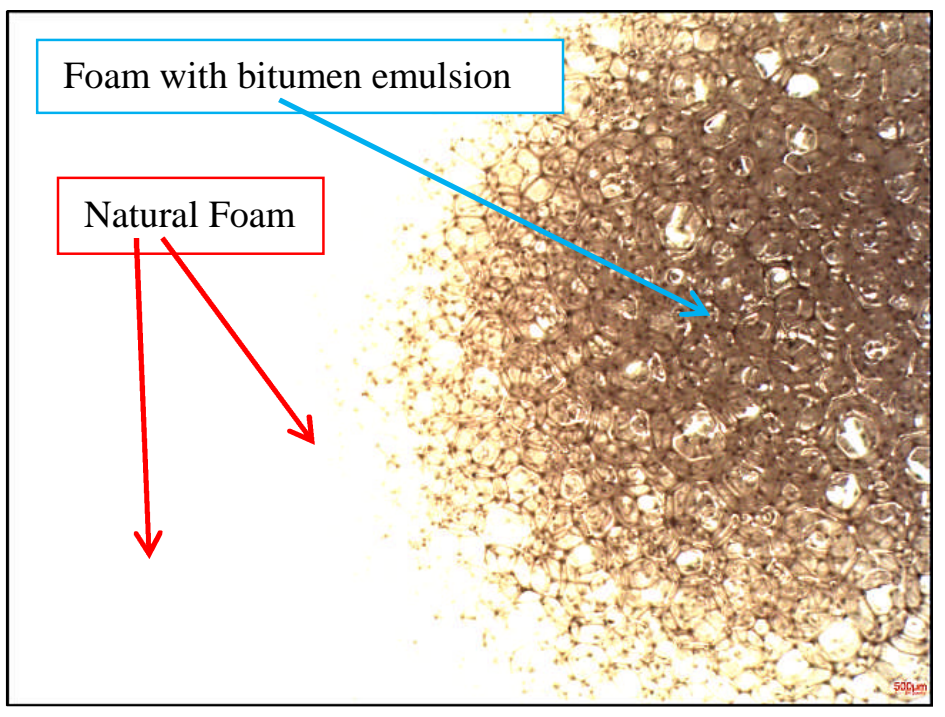

Fig. 1. Image of foam during bitumen emulsion application. 
Fig. 2. Foam after treating with bitumen emulsion.

340

341

342

343

344

345

346

347

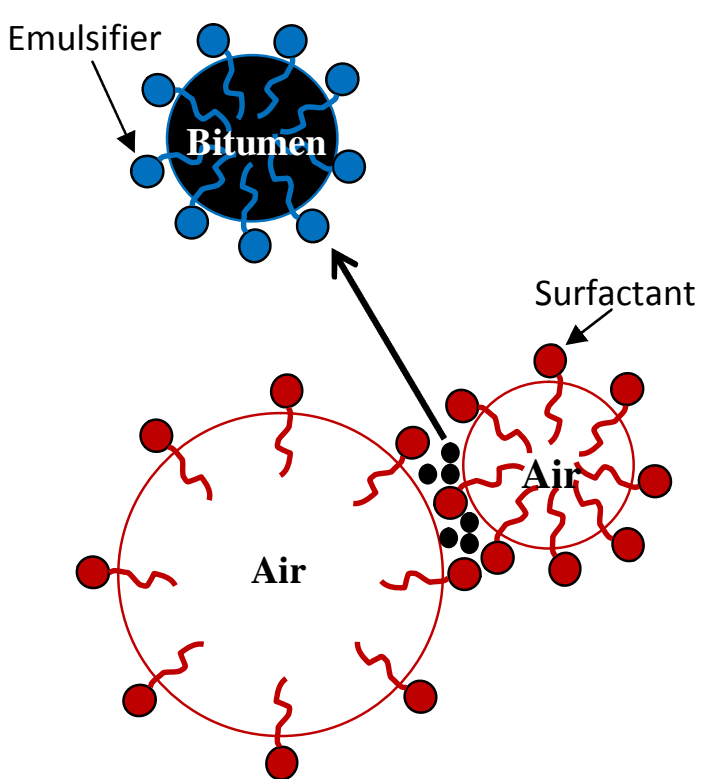

351

352

353

354

355

356

357
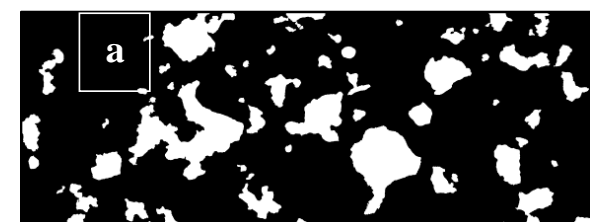

55
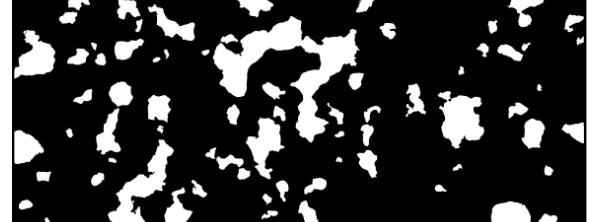

Fig. 3. The interaction between foam bubbles and bitumen emulsion.
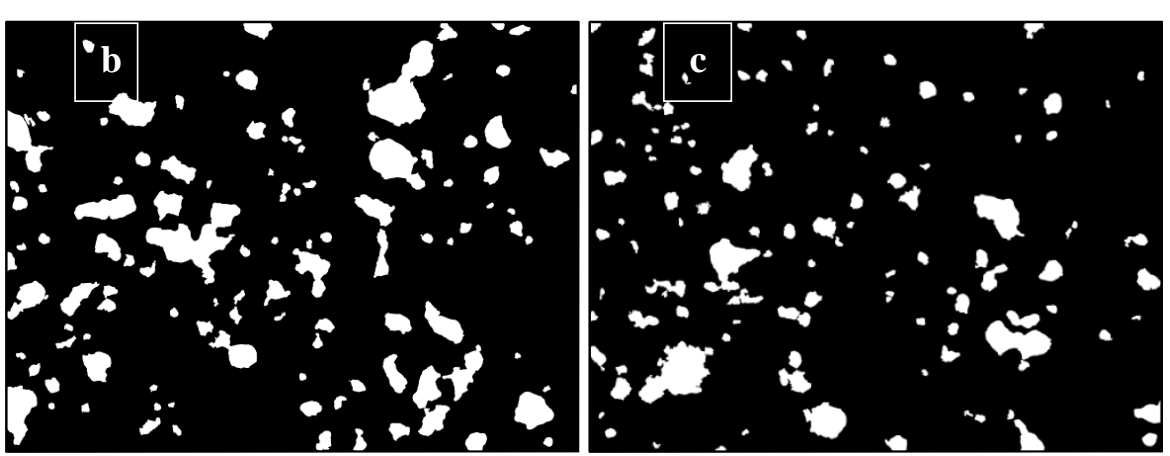

Fig. 4. Typical binary images $[15.43 \mathrm{~mm} \times 11.57 \mathrm{~mm}]$ a) FC3, b) FC6 and c) FC9. 


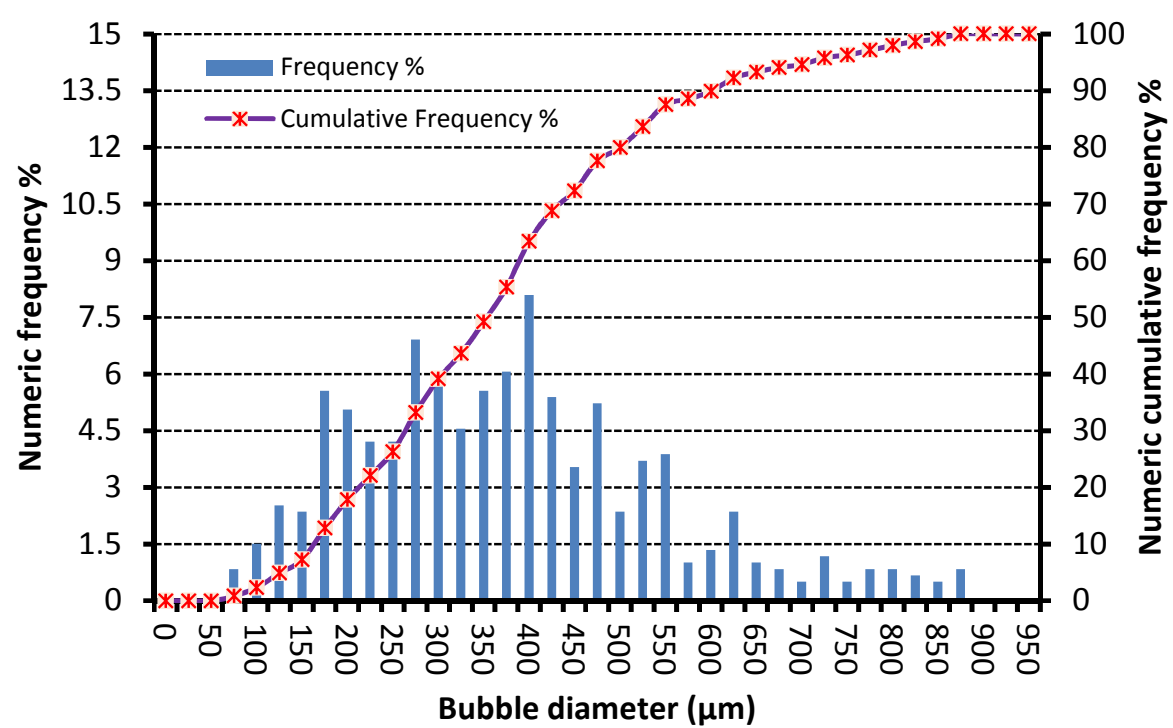

Fig. 5. Numeric bubble size distribution and cumulative frequency of foam.

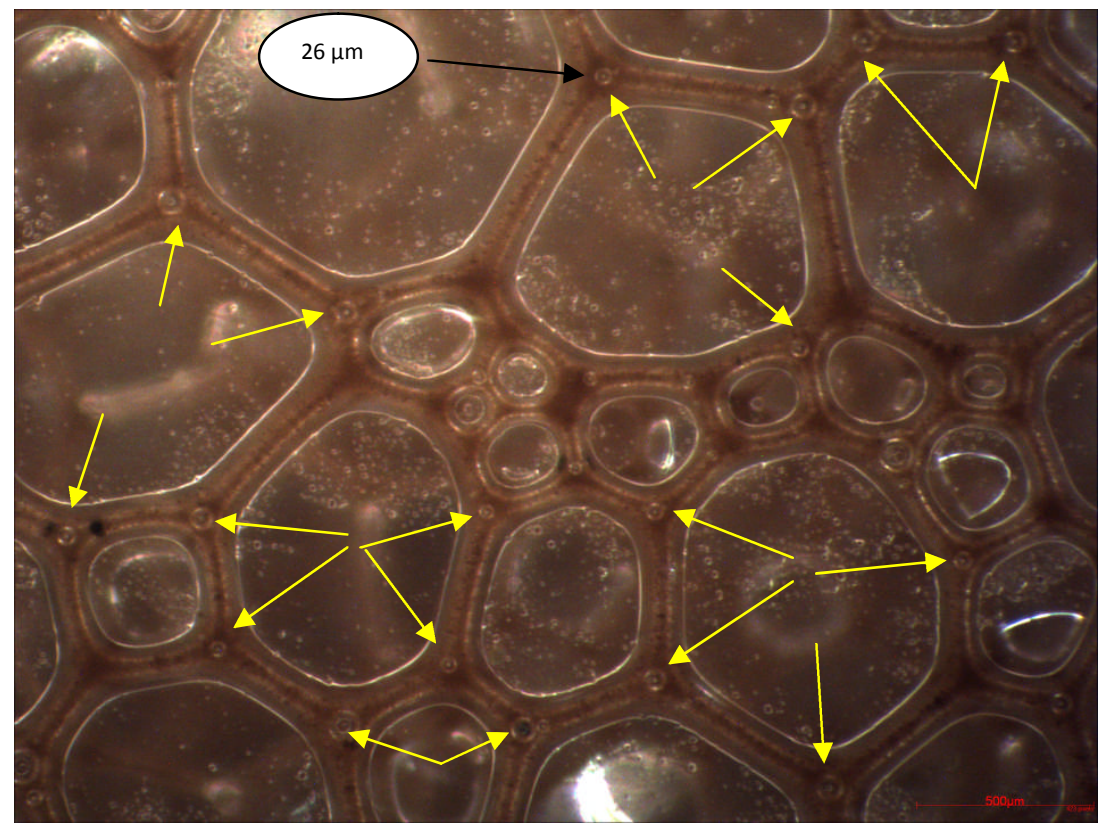

Fig. 6. Foam image showing voids with diameters less than $100 \mu \mathrm{m}$ by applying a microscope glass slide to the foam surface. 

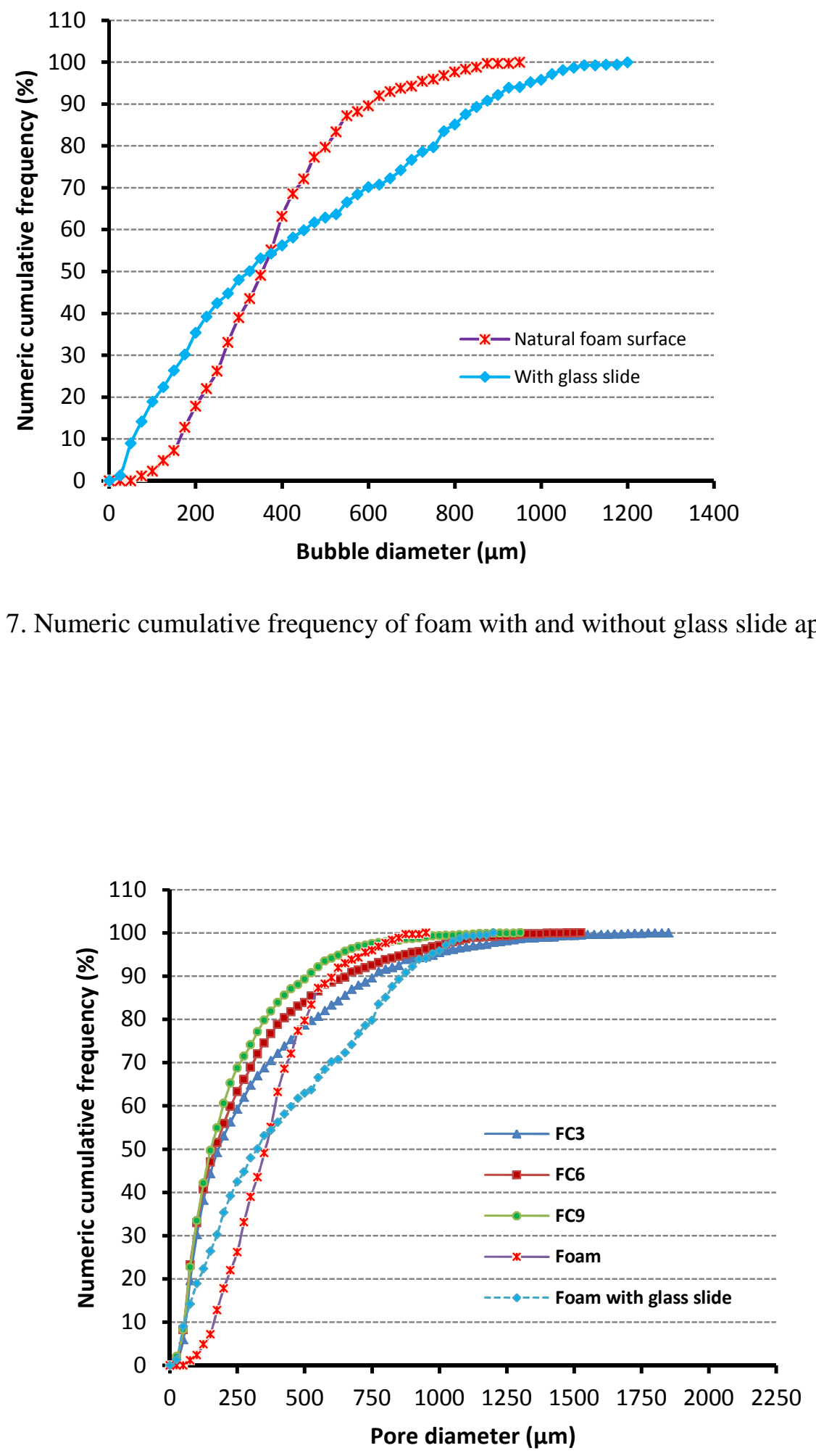

Fig. 8. Numeric cumulative frequency of bubble/pore diameters of foam and foamed concrete mixes. 
Table 2. Parameters of pores sizes and circularity of foam and mixes.

\begin{tabular}{l|c|c|c|c}
\cline { 2 - 4 } & Foam & FC3 & FC6 & FC9 \\
\hline$(\mathrm{D} \text { or O })_{50}{ }^{*}(\mu \mathrm{m})$ & 325 & 180 & 175 & 165 \\
$(\mathrm{D} \text { or O })_{90}{ }^{*}(\mu \mathrm{m})$ & 600 & 750 & 650 & 525 \\
$(\mathrm{D} \text { or O })_{50}{ }^{* *}(\mu \mathrm{m})$ & 470 & 770 & 685 & 550 \\
$(\mathrm{D} \text { or O })_{90}{ }^{* *}(\mu \mathrm{m})$ & 765 & 1425 & 1225 & 990 \\
$\mathrm{~F}_{\text {circ50 }}$ & & 0.53 & 0.59 & 0.65 \\
$\mathrm{~F}_{\text {circ90 }}$ & & 0.75 & 0.80 & 0.84 \\
\hline
\end{tabular}

390 Note: Diameter of bubbles (D) and voids (O) derived either from cumulative distribution based on numeric of 391 bubbles/voids ${ }^{(*)}$ at each size or on area of bubbles/voids ${ }^{(* *)}$ at each size.

392

393

394

395

396

397

398

399

400

401

402

403

404

405
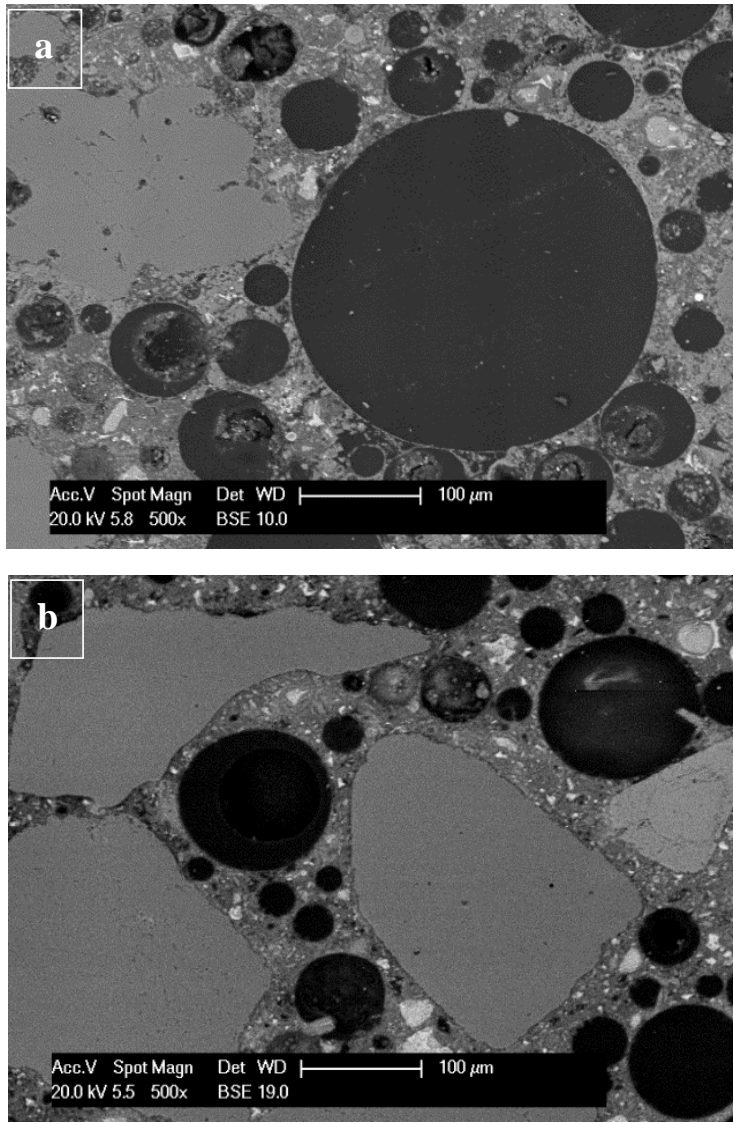

406

407

408

409

410

411

412

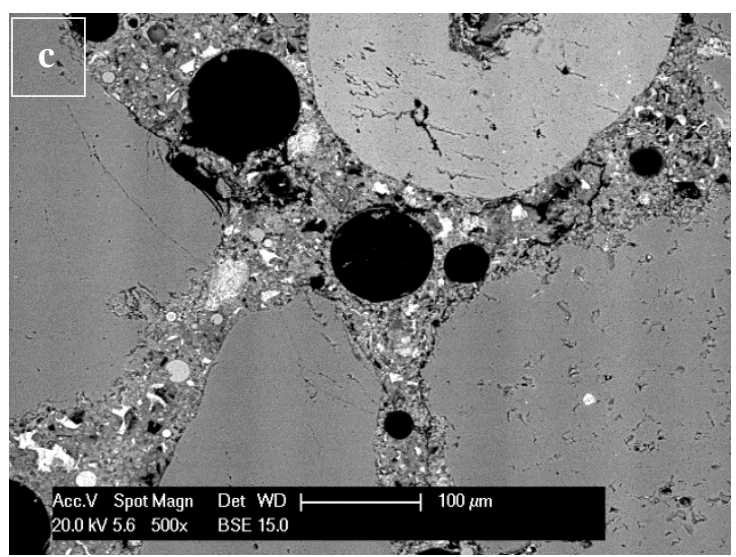

Fig. 9. SEM images of foamed concrete mixes a) FC3, b) FC6 and c) FC9.
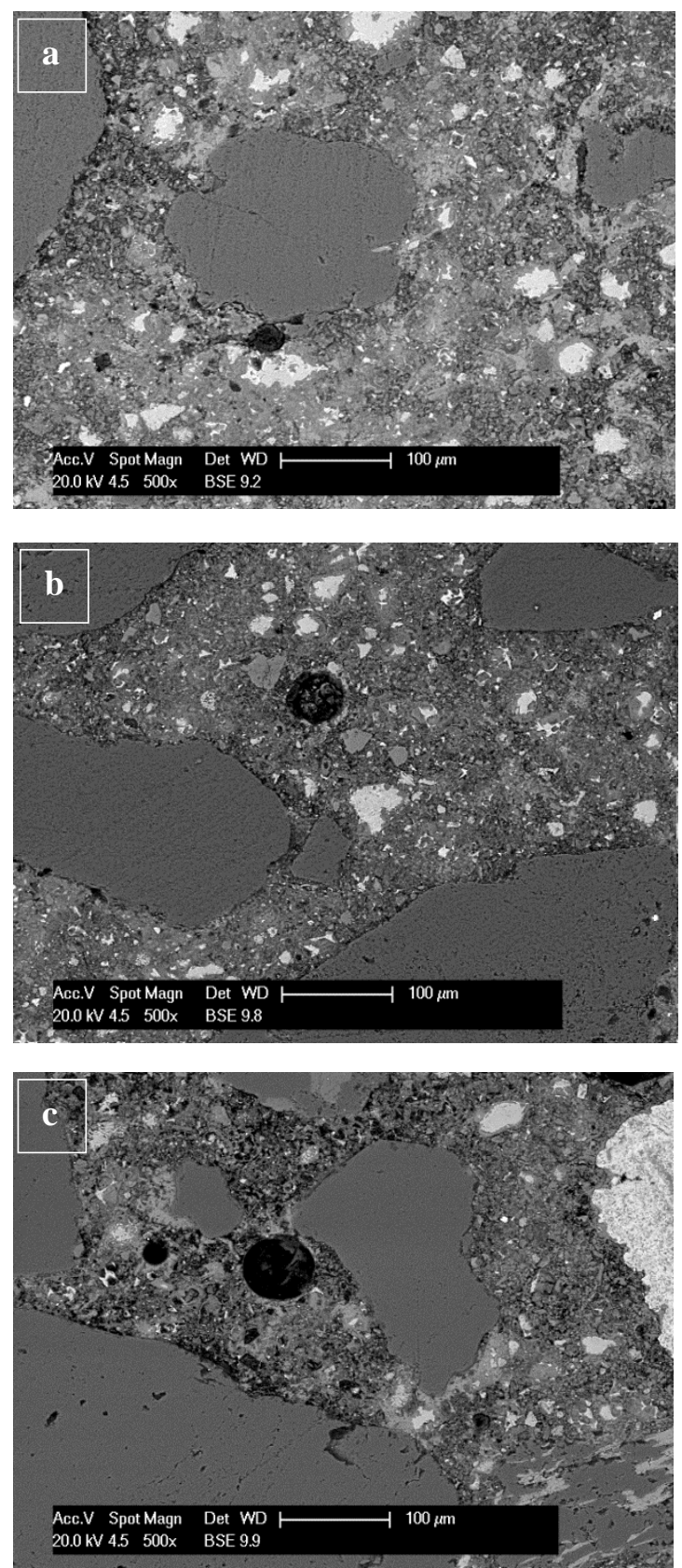

Fig. 10. SEM images for mixes without foam a) 1300 b) 1600 and c) $1900 \mathrm{~kg} / \mathrm{m}^{3}$. 


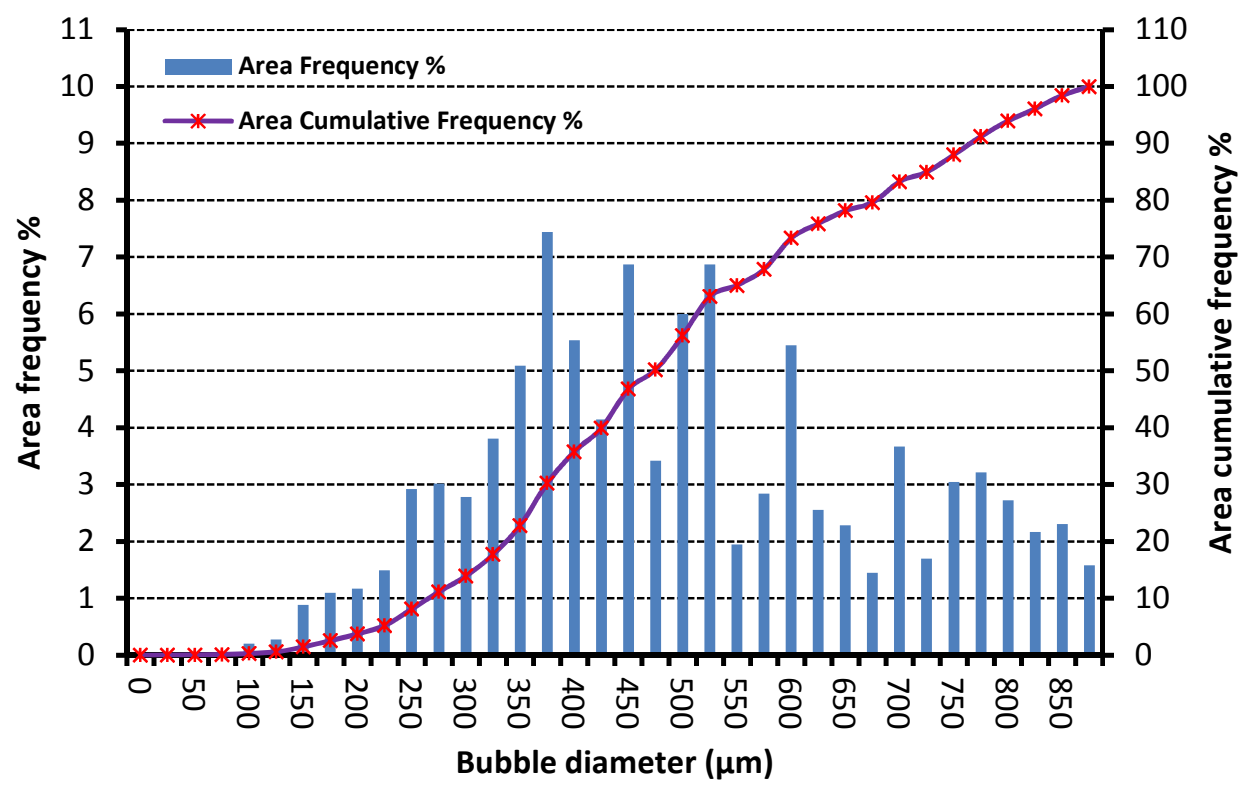

Fig. 11. Area bubble size distribution and cumulative frequency of foam.

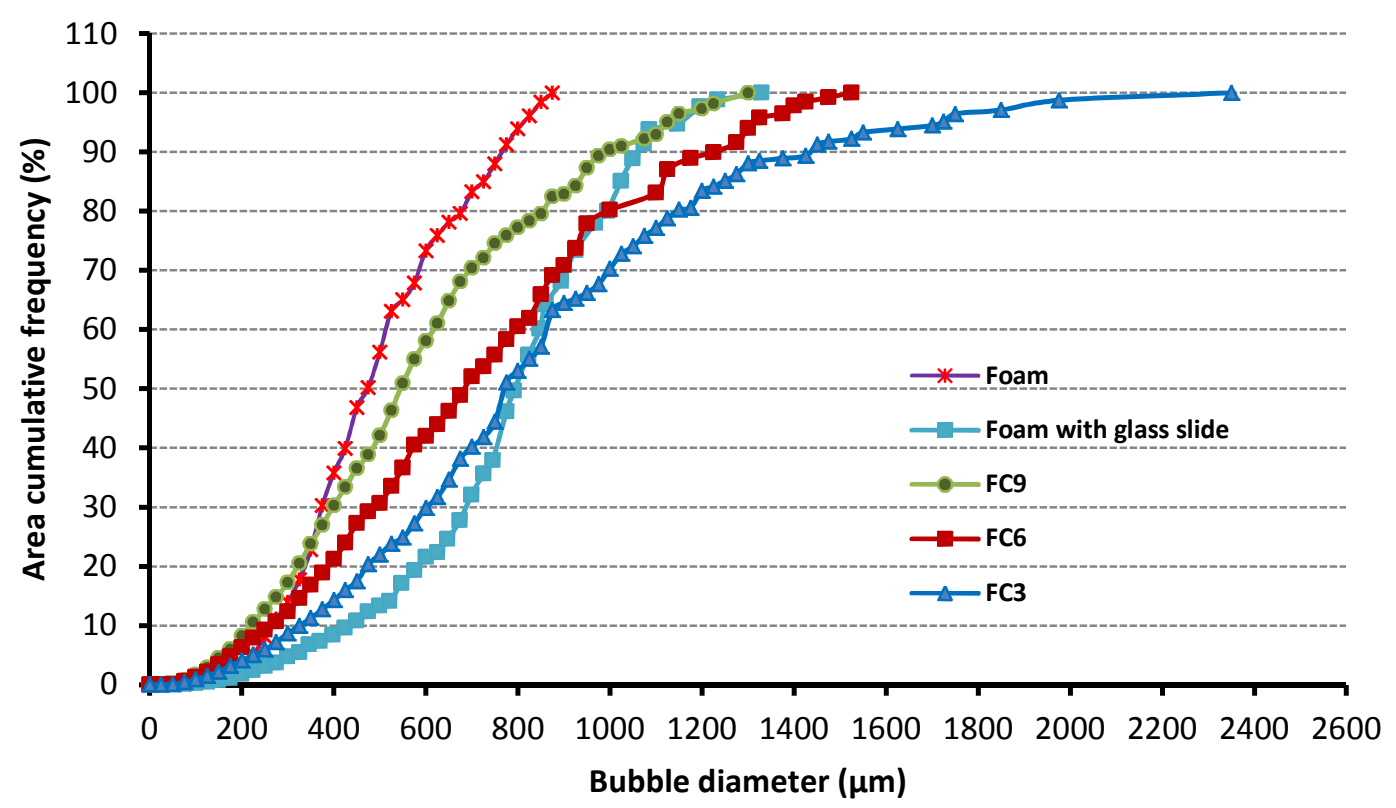

Fig. 12. Area cumulative frequency of bubble/pore diameters of foam and foamed concrete mixes.

417

418

419

420 

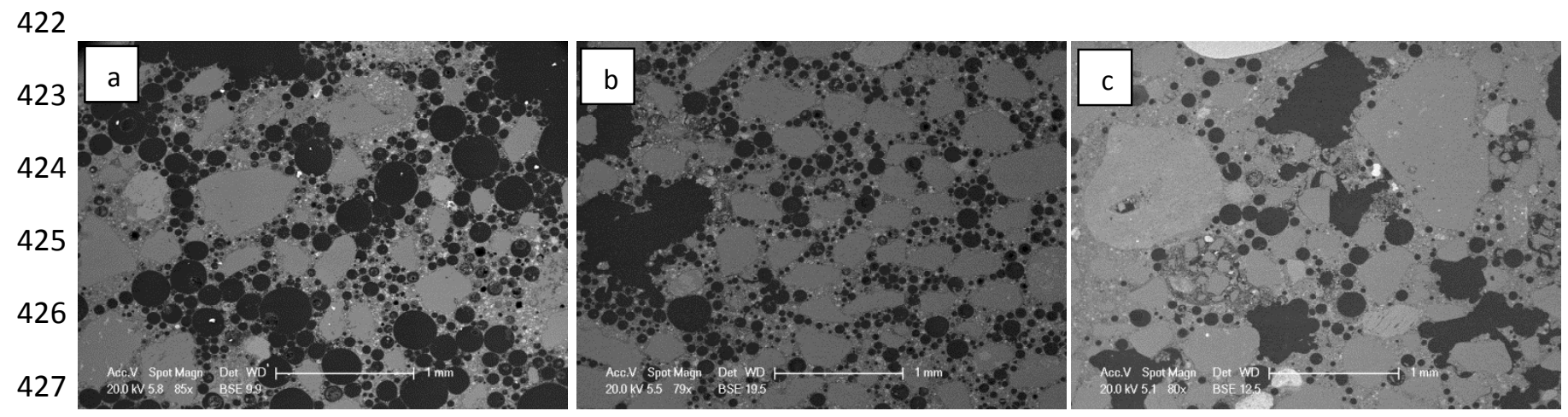

428

Fig. 13. SEM images of foamed concrete mixes showing the bubble merging a) FC3, b) FC6 and c) 429 FC9.

430

431

432

Circularity factor

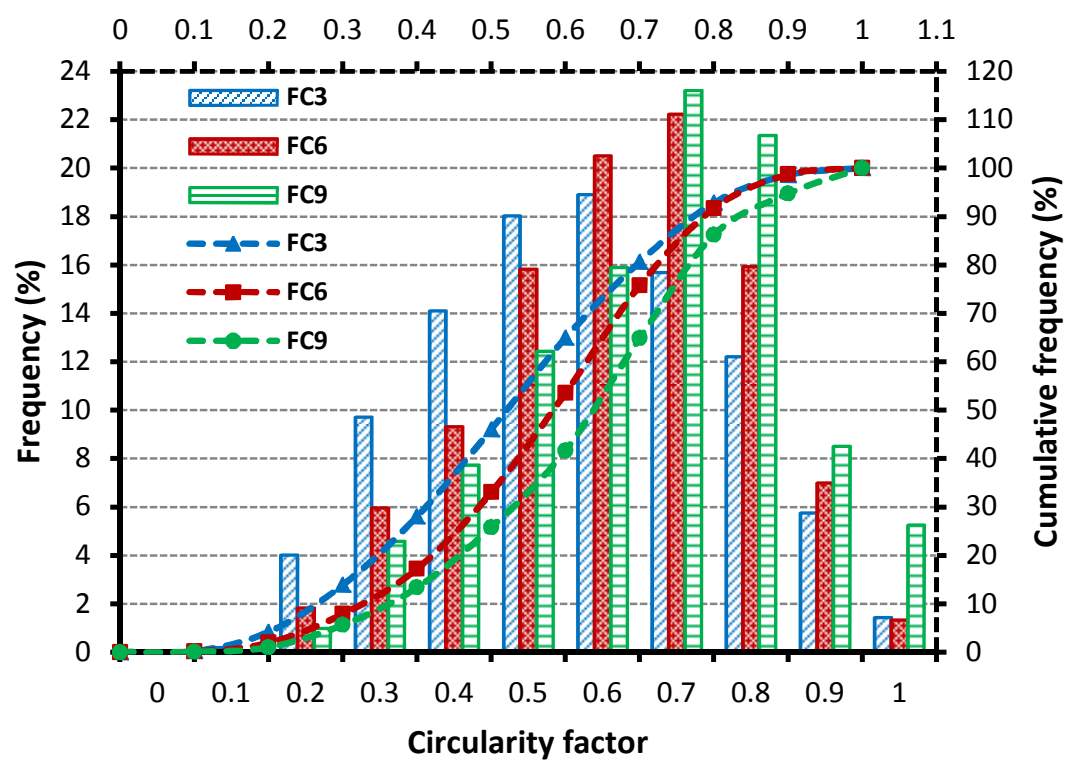

433

Fig. 14. Circularity factor of foamed concrete mixes.

435

436

437

438

439

440

441 


\section{References}

443 1. Nambiar, E. and K. Ramamurthy, Air-void characterisation of foam concrete. Cement and

2. Ramamurthy, K., E.K. Kunhanandan Nambiar, and G. Indu Siva Ranjani, A classification of studies on properties of foam concrete. Cement and Concrete Composites, 2009. 31(6): p. 388-396.

3. Othuman, M.A. and Y.C. Wang, Elevated-temperature thermal properties of lightweight foamed concrete. Construction and Building Materials, 2011. 25(2): p. 705-716.

4. Jitchaiyaphum, K., T. Sinsiri, and P. Chindaprasirt, Cellular Lightweight Concrete Containing Pozzolan Materials. Procedia Engineering, 2011. 14(0): p. 1157-1164.

5. Kearsley, E., The Effect of High Volume of Ungraded Fly Ash on the Properties of Foamed Concrete, in School of Civil Engineering 1999, The University of Leeds: Leeds.

6. Yu, X.G., et al., Pore Structure and Microstructure of Foam Concrete. Advanced Materials Research, 2011. 177: p. 530-532.

7. Just, A. and B. Middendorf, Microstructure of high-strength foam concrete. Materials Characterization, 2009. 60(7): p. 741-748.

8. BS EN 197-1, Cement-Part 1: Composition, Specifications and Conformity Criteria for Common Cements, in British Standards Institution, London. 2011.

9. BS 882, Specification for aggregates from natural sources for concrete. British Standards Institution, London, 1992.

10. ASTM C144, Standard Specification for Aggregate for Masonry Mortar. 1987, American Society for Testing and Materials.

11. Jones, M. and A. McCarthy, Preliminary views on the potential of foamed concrete as a structural material. Magazine of concrete research, 2005. 57(1): p. 21-31.

12. Nambiar, E.K.K. and K. Ramamurthy, Sorption characteristics of foam concrete. Cement and concrete research, 2007. 37(9): p. 1341-1347.

13. Nambiar, E.K.K. and K. Ramamurthy, Fresh state characteristics of foam concrete. Journal of materials in civil engineering, 2008. 20: p. 111.

14. BS EN 480-11, Admixtures for concrete, mortar and grout- Test methods- Part 11: Determination of air void characteristics in hardened concrete. 2005: British Standards Institution, London.

15. Scheffler, M. and P. Colombo, Cellular ceramics: structure, manufacturing, properties and applications. 2005: WILEY-VCH Verlag GmbH \& Co. KGaA. 
486 Fig. 1. Image of foam during bitumen emulsion application.

487 Fig. 2. Foam after treating with bitumen emulsion.

488 Fig. 3. The interaction between foam bubbles and bitumen emulsion.

489 Fig. 4. Typical binary images $[15.43 \mathrm{~mm} \times 11.57 \mathrm{~mm}]$ a) FC3, b) FC6 and c) FC9.

490 Fig. 5. Numeric bubble size distribution and cumulative frequency of foam.

491 Fig. 16. Foam image showing voids with diameters less than $100 \mu \mathrm{m}$ by applying a microscope glass 492 slide to the foam surface.

493 Fig. 7. Numeric cumulative frequency of foam with and without glass slide application.

494 Fig. 8. Numeric cumulative frequency of bubble/pore diameters of foam and foamed concrete mixes.

495 Fig. 9. SEM images of foamed concrete mixes a) FC3, b) FC6 and c) FC9.

496 Fig. 10. SEM images for mixes without foam a) 1300 b) 1600 and c) $1900 \mathrm{~kg} / \mathrm{m}^{3}$.

497 Fig. 11. Area bubble size distribution and cumulative frequency of foam.

498 Fig. 12. Area cumulative frequency of bubble/pore diameters of foam and foamed concrete mixes.

499 Fig. 13. SEM images of foamed concrete mixes showing the bubble merging a) FC3, b) FC6 and c) 500 FC9.

501 Fig. 14. Circularity factor of foamed concrete mixes.

502

503 